\title{
A FUNÇÃO E A IMPORTÂNCIA DAS DISCIPLINAS PROPEDÊUTICAS NA ESTRUTURA CURRICULAR DOS CURSOS DE DIREITO NO BRASIL*
}

\author{
Abili Lázaro Castro de Lima**
}

RESUMO: O artigo tem por escopo demonstrar a importância e a necessidade das disciplinas propedêuticas (as quais tem por objetivo a formação geral, humanística, crítica e reflexiva), no eixo de formação fundamental dos bacharéis de direito, consoante as novas diretrizes curriculares dos cursos de direito no Brasil, introduzidas pela Resolução n. 9 de 24 de setembro de 2004, do Conselho Nacional de Educação.

"Apesar das ruínas e da morte

Onde sempre acabou cada ilusão

A força dos meus sonhos é tão forte

Que de tudo renasce a exaltação E nunca as minhas mãos estão vazias”.

D. Sophia de Mello Breyner Andresen

Ao analisarmos o mundo em que vivemos, podemos contemplar várias conquistas civilizacionais: a democracia, o

* Dedico este artigo aos estudantes do curso de direito da Universidade Federal do Paraná, os quais são a razão de ser da minha cátedra.

** Mestre e Doutor em Direito pela Universidade Federal do Paraná. Professor da disciplina Direito e Sociedade no curso de graduação em direito e de Sociologia do Direito no programa de pós-graduação em direito da Universidade Federal do Paraná. Avaliador do INEP. sufrágio universal, o exercício da liberdade, a conquista dos direitos em várias dimensões. Todavia, não percebermos as lutas que tiveram que ser travadas contra o autoritarismo, o despotismo e a opressão, bem como os sacrifícios e as condições adversas que as pessoas no passado tiveram que superar para que hoje possamos usufruir de tais conquistas. Além disso, não nos damos conta que a manutenção de tais conquistas depende de nossa atuação em prol da sua defesa. Nada garante que possamos vivenciar, a qualquer momento, um retrocesso civilizatório, tal como aconteceu nas nefastas experiências do totalitarismo. ${ }^{1}$ Portanto, é necessário que

\footnotetext{
${ }^{1}$ Nesta hipótese, podemos dizer, parafraseando Marx na obra "O 18 Brumário", que teria vindo pela primeira vez com uma tragédia, depois como
} 
tenhamos consciência que tais conquistas se encontram num equilíbrio precário e que devemos estar atentos com os perigos que rondam nosso cotidiano.

$\mathrm{Na}$ década de noventa, no âmbito do ensino jurídico no Brasil, também podemos encontrar manifestações de conquistas importantes para o seu aprimoramento, por meio da construção de um modelo de ensino jurídico que conjuga a formação humanista, reflexiva e crítica com a formação profissionalizante e prática, superando o modelo ultrapassado do profissional tecnicista, que vigorou nas décadas de setenta e oitenta. $\mathrm{O}$ novo modelo encontra respaldo na LDB - Lei de Diretrizes e Bases da Educação (Lei n. ${ }^{\circ}$ 9.394/96), nas diretrizes curriculares editadas pelo Ministério da Educação, bem como em várias obras editadas, dentre elas destacam-se as editadas pela Comissão de Ensino Jurídico do Conselho Federal da Ordem dos Advogados do Brasil. ${ }^{2}$

Para que seja possível avaliar a importante conquista do novo modelo e os

uma farsa, nos seguintes termos: "Hegel observa em uma de suas obras que todos os fatos e personagens de grande importância na história do mundo ocorrem, por assim dizer, duas vezes. E esqueceu-se de acrescentar: a primeira vez como tragédia, a segunda como farsa". In: O 18 Brumário e Cartas a Kugelmann. 7.ed. Rio de Janeiro: Paz e Terra, 2002, p. 21.

2 OAB ENSINO JURÍDICO: Diagnóstico, Perspectivas e Propostas, 2.ed. Conselho Federal da OAB, Brasília, 1996; OAB ENSINO JURÍDICO: Novas Diretrizes Curriculares, Conselho Federal da OAB, Brasília, 1996; OAB ENSINO JURÍDICO: Parâmetros para Elevação de Qualidade e Avaliação, Conselho Federal da OAB, Brasília, 1997; ENSINO JURÍDICO OAB: 170 anos de cursos jurídicos no Brasil, Conselho Federal da OAB, Brasília, 1997. perigos que ele vem se defrontando, os quais constituem um retrocesso histórico, procederemos uma análise dos modelos de ensino jurídico que o antecederam. Tais ameaças manifestam-se por meio de propostas que procuram resgatar o modelo do profissional tecnicista, as quais priorizam a especialização dos bacharéis de direito nas disciplinas profissionalizantes (também denominadas de dogmáticas), bem como propõem um caráter instrumental ao ensino jurídico, o qual deveria estar voltado para a formação de advogados e para capacitação dos bacharéis para o Exame da OAB, em detrimento das disciplinas propedêuticas, que proporcionam uma formação humanista, reflexiva e crítica aos bacharéis.

A professora Eliane Botelho Junqueira realiza um interessante estudo ${ }^{3}$ acerca dos modelos dos cursos jurídicos no Brasil, identificando o modelo do bacharel humanista e do profissional tecnicista.

$\mathrm{O}$ primeiro modelo nasce com o surgimento dos cursos de ciências jurídicas e sociais, pela lei de 11/08/1827, em Olinda e São Paulo. Os cursos tinham por objetivo proporcionar uma formação humanista e generalista aos bacharéis de direito, voltada a capacitá-los para o desempenho das atividades político-administrativas em substituição à burocracia portuguesa, visando a construção do Estado nacional, cuja independência havia sido recentemente conquistada. ${ }^{4}$

Jayme Paviani e José C. Pozenato resgatam o papel dos cursos jurídicos para

3 JUNQUEIRA, E. B. A Sociologia Jurídica no Brasil: introdução ao debate atual. Rio de Janeiro: Lumen Juris, 1993.

${ }^{4}$ JUNQUEIRA, E. B. Op. cit., p. 16-22. 
o atendimento das necessidades sociais do Brasil Império, bem como de seu papel embrionário do surgimento das universidades:

No lugar da Universidade, seguiu-se no Brasil o modelo francês, de inspiração napoleônica, de criar escolas profissionais autônomas, para a formação de profissionais liberais: médicos, engenheiros e advogados. Esse modelo corresponde às necessidades da ordem social vigente, no sentido de reforçá-la. A Universidade, nesse contexto, teria uma função "desestabilizadora", papel aliás desempenhado em parte pelas Faculdades de Direito, onde se desenvolveu a ideologia republicana. No período imperial, essas faculdades foram uma espécie de embrião de Universidade. ${ }^{5}$

O modelo do profissional tecnicista nasce com a Reforma Universitária (Lei n. ${ }^{\circ}$ 5.540/ 68) e se concretiza na reforma curricular dos cursos de direito (Resoluções n. ${ }^{\circ}$ 03/72 e 15/73). As razões da implementação da Reforma Universitária foram assim definidas por Paviani e Pozenato:

O principal motivo que levou à Reforma Universitária brasileira foi a tomada de consciência de que não havia Universidades no país e sim apenas instituições de ensino superior, agências de formação de profissionais liberais. A atividade de formação profissional, que deveria ser decorrência da atividade universitária, era na realidade sua meta exclusiva. Em conseqüência, a Universidade brasileira não era um centro de ciência e de cultura e também não correspondia às funções que deveria exercer na sociedade. [...]

Um motivo mais imediato, e de maior força, foi a nova situação criada no país com o surto desenvolvimentista deflagrado pelo Governo de Juscelino Kubitscheck. O desenvolvimento mostrou a necessidade de uma diversificação

${ }^{5}$ PAVIANI, J. e POZENATO, J. C. A Universidade em debate. Caxias do Sul: EDUCS, 1980, p. 66. maior de habilitações profissionais, além das tradicionais profissões liberais; passou a exigir a participação da Universidade na elaboração de novos conhecimentos, científicos e tecnológicos; e, sobretudo, provocou um crescimento explosivo da demanda pela formação universitária, até então buscada somente pelas elites sociais. Diante de todas essas novas exigências, constatou-se que a Universidade brasileira se encontrava despreparada, obsoleta, elitista, bacharelesca, em suma, afastada da missão cultural e científica que dela passava agora a esperar a sociedade (impunha-se, agora, com clareza, à consciência nacional, a necessidade de uma reforma universitária)". ${ }^{6}$

Os objetivos da Reforma Universitária foram: “a) modernização administrativa; b) renovação do conceito de ensino superior; c) integração da Universidade com o desenvolvimento da sociedade e d) redefinição do papel do Estado com relação à Universidade". 7

Neste contexto, o modelo do ensino jurídico humanista entrou em crise, uma vez que se encontrava divorciado dos objetivos da Reforma Universitária. Na década de sessenta, o CEPED - Centro de Estudos e Pesquisas no Ensino do Direito desenvolveu estudos questionando o bacharelismo, consoante leciona Eliane Botelho Junqueira:

O CEPED, que funcionou durante o período de 1967-1972, representou a tentativa de alguns professores de direito, sob a orientação de David Trubek, então Consultor Jurídico da United States for Internacional Development (USAID), de atualizar a formação do profissional de direito, tendo em vista as novas demandas do mercado empresarial brasileiro. [...]

\footnotetext{
${ }^{6}$ PAVIANI, J. e POZENATO, J. C. Op. cit., p. 73-74.

${ }^{7}$ PAVIANI, J. e POZENATO, J. C. Op. cit., p. 74-75.
} 
A este projeto de formação de juristas técnicos aptos a atenderem às necessidades derivadas do processo de desenvolvimento, somou-se a reformulação dos cursos de direito em 1972, na esteira da reforma universitária implantada em $1968 .^{8}$

As consequiências negativas do modelo do profissional tecnicista foram evidenciadas por José Eduardo Faria e Celso Fernandes Campilongo, ao analisarem a Reforma Universitária de 1968:

[...], na lógica dos autores dessa reforma, às instituições universitárias caberia um papel eminentemente pragmático e utilitarista: ou seja, elas deveriam concentrar sua atenção na formação de quadros técnicos e gerenciais necessários à implementação do tipo de desenvolvimento econômico então vigente. Aos idealizadores dessa reforma apenas interessava, em nome dos objetivos "maiores" do regime burocrático-militar pós-64, substituir o conceito "humanista" de formação cultural por uma progressiva racionalização e especialização do ensino superior, sob os requisitos da eficácia econômica e do avanço tecnológico.

Precedida por um espúrio processo de afastamento das lideranças políticas e intelectuais, tal reforma acabou sendo manipulada pelos setores mais conservadores do establisment acadêmico. Estes setores, agindo em consonância com os interesses do regime, procuram integrar as ciências básicas a uma educação exclusivamente profissionalizante, valendo-se dessa estratégia mais como instrumento de controle políticoideológico da vida acadêmica do que propriamente de renovação do ensino e da pesquisa.

A educação a nível universitário converteu-se, então, numa banal e descompromissada atividade de informações genéricas e/ou profissionalizantes - com os alunos sem saber ao certo o que fazer diante de um conhecimento transmitido de maneira desarticulada e pouco sistemática, sem rigor metodológico, sem

\footnotetext{
8 JUNQUEIRA, E. B. Op. cit., p. 22-23.
}

reflexão crítica e sem estímulo às investigações originais. A ênfase à "rentabilidade" educacional anulou por completo a função formativa da Universidade brasileira, mediante uma crescente marginalização das atividades criativas e críticas. Como decorrência, as estruturas universitárias se verticalizaram, em detrimento da autonomia acadêmica e da flexibilidade horizontal de projetos interdisciplinares, ao mesmo tempo em que os corpos docentes se dispersaram entre departamentos estanques e fechados em sua própria rotina burocrática.

Ao voltar-se somente à produção de grandes contingentes de diplomados, dos quais a maioria absoluta destacava-se pela discutível qualidade de sua formação teórica e técnica, a Universidade brasileira progressivamente deixou-se transformar em simples agência cartorial transmissora de idéias pré-concebidas, incapaz de oferecer ao aluno respostas satisfatórias ao entendimento do meio ambiente e de preparação em termos de qualificação profissional. Esse processo de abastardamento do ensino superior tornou-se, no decorrer do regime pós-64, cada vez mais problemático, disfuncional e desagregador. [...]. ${ }^{9}$

$\mathrm{Na}$ esteira das lições anteriormente reproduzidas, Paviani e Pozenato reforçam os efeitos da formação profissionalizante em detrimento da formação humanística, reflexiva e crítica, sob os auspícios da Reforma Universitária de 1968:

[...] Numa perspectiva mais ampla, porém, constata-se que a Universidade brasileira apenas diversificou e multiplicou as carreiras oferecidas - embora não tanto quanto o necessário, diga-se de passagem - mas permaneceu basicamente voltada para a formação profissional. A aparente modernização de fato foi a conservação da idéia de Universidade como mera agência de ensino.

\footnotetext{
${ }^{9}$ FARIA, J. E. e CAMPILONGO, C. F. A Sociologia
} Jurídica no Brasil. Porto Alegre: Sérgio Antônio Fabris ed., 1991, p. 10-11. 
Some-se a isso que, como as novas profissões criadas visam o desempenho de funções técnicas, a formação humana tende a ocupar sempre menos lugar na educação superior brasileira. Essa formação é no entanto absolutamente necessária para que o profissional se torne capaz de colocar a técnica a serviço dos homens, sem risco de usá-la contra os homens. Numa Universidade tecnológica, não cabe o pensamento crítico e portanto a reflexão globalizante sobre o homem e a sociedade. Pensamento e reflexão tão vitais para o desenvolvimento como a própria tecnologia. ${ }^{10}$

Ao verificarmos as mazelas causadas pela concepção profissionalizante e tecnicista implementada pela Reforma Universitária de 1968, já podemos antever os perigos que representam as propostas que pretendem ressuscitar o referido modelo. Todavia, antes de realizarmos uma análise dos seus efeitos negativos, levando-se em consideração a sua hipotética implementação no contexto contemporâneo, é importante discorremos sobre a nova concepção de ensino jurídico implementada pela LDB e pelas diretrizes curriculares dos cursos de direito definidas pelo Ministério da Educação a partir de 1994, a qual colocou a última pá de cal sobre o modelo do profissional tecnicista.

O advento da LDB em 1994 inaugurou um novo panorama no ensino no Brasil, ao fortalecer a descentralização administrativa e acadêmica, possibilitando uma flexibilização curricular em contrapartida aos currículos mínimos herdados da reforma curricular dos cursos jurídicos ocorrida nos anos setenta. $\mathrm{O}$ ensino superior tem por finalidade a formação do pensamento reflexivo e a

\footnotetext{
${ }^{10}$ PAVIANI, J. e POZENATO, J. C. Op. cit., p. 104.
}

formação de profissionais, conforme se depreende dos incisos I e II, do art. 43, da LDB. ${ }^{11}$

Sob a inspiração da LDB, o Ministério da Educação editou a Portaria n. ${ }^{\circ}$ 1.886/94 que inseriu a flexibilização curricular no contexto dos cursos de direito, por meio das disciplinas optativas, áreas de habilitação e atividades complementares. Sem descurar das disciplinas profissionalizantes, enfatizou também o ensino reflexivo ao estabelecer a obrigatoriedade dos currículos contemplarem matérias fundamentais, tais como Filosofia (geral e jurídica); Ética (geral e profissional), Sociologia (geral e jurídica), Economia e Ciência Política (com Teoria do Estado). Acerca da interdisciplinariedade prevê que "as demais matérias e novos direitos serão incluídos nas disciplinas em que se desdobrar o currículo pleno de cada curso, de acordo com as peculiaridades e com observância de interdisciplinariedade" (art. 6. ${ }^{\circ}$, parágrafo único).

No que concerne à importância das disciplinas fundamentais e sua articulação com a interdisciplinariedade, são precípuos os ensinamentos de Paulo Luiz Neto Lôbo:

A interdisciplinariedade, na dimensão externa ao saber dogmático jurídico, enlaça-se com matérias que contribuem para a formação do profissional de Direito, notadamente estimuladoras da reflexão crítica e da atuação político-institucional, que a sociedade cada vez mais dele reclama. Assim, a interessante

11 Art. 43. A educação superior tem por finalidade: I - estimular a criação cultural e o desenvolvimento do espírito científico e pensamento reflexivo; II - formar diplomados nas diferentes áreas do conhecimento, aptos para a inserção em setores profissionais e para a participação no desenvolvimento da sociedade brasileira, e colaborar na sua formação contínua;" 
abertura para as Ciências Sociais, Humanas, Políticas, para a Filosofia, incluindo as perspectivas lógica e ética, para a Psicologia, para a Informática, para a Ciência da Linguagem. [...]

[...] O conteúdo mínimo é assim divido em três partes:

a) a parte fundamental e reflexivo-crítica;

b) a parte profissionalizante ou técnica-jurídica;

c) a parte prática.

Sempre sustentei, em trabalhos anteriores, que a formação jurídica assenta-se neste tripé. O curso jurídico, para bem desempenhar suas finalidades, deve atingir, de modo interindependente, a tríplice função de:

a) formação fundamental e sócio-política, que forneça ao aluno uma sólida base humanística e de capacitação crítica; b) formação técnico-jurídica, que o capacite ao exercício competente de sua profissão reconhecendo que as disciplinas dogmáticas admitem espaço à reflexão crítica; c) formação prática, oferecendo-lhes os meios para aplicar os conhecimentos obtidos.

A matéria Filosofia (geral e jurídica), que pode estar desdobrada em mais de uma disciplina, deve incluir no conteúdo programático o estudo da ética geral e da ética profissional. Há espaço para inclusão do inquietante tema da bioética, que cada vez mais convida à meditação dos juristas.

A obrigatoriedade da Sociologia jurídica rende homenagem à luta histórica de grandes sociólogos do Direito, no Brasil, como Cláudio Souto que, em suas obras sempre reclamou a imprescindibilidade desses estudos para a formação do profissional do Direito, abrindolhes horizontes para além da dogmática jurídica. Com a Ciência Política pretende-se ir mais longe que o estudo clássico da teoria do Estado, embora esta continue. Interessa ao estudante de Direito que amplie sua compreensão aos fenômenos e estruturas políticas, à teoria do poder (e não apenas do poder político formal), à deontologia política. [...] $]^{12}$

12 LÔBO, P. L. Neto. O novo conteúdo mínimo dos cursos jurídico. In: OAB ENSINO JURÍDICO: Novas Diretrizes Curriculares, Conselho Federal da OAB, Brasília, 1996. p. 10-11.
As novas diretrizes curriculares dos cursos de direito, instituídas pela Resolução n. ${ }^{\circ} 9$ de 24 de setembro de 2004, do Conselho Nacional de Educação, prevêem no seu art. 4. ${ }^{\circ}$, inciso VI, a necessidade, dentre outras, que o curso de direito possibilite a formação profissional despertando "a utilização do raciocínio jurídico, de argumentação, de persuasão e de reflexão crítica", devendo o curso, para tanto, contemplar tanto no seu Projeto Pedagógico quanto na sua estrutura curricular, conteúdos e atividades que atendam a três eixos de formação: 1) fundamental; 2) profissional e 3) prática (art. 5. ${ }^{\circ}$ ).

No que pertine ao eixo de formação fundamental, as novas diretrizes curriculares ampliam o leque de conteúdos essenciais: Antropologia, Ciência Política, Economia, Ética, Filosofia, História, Psicologia e Sociologia.

O novo modelo de ensino jurídico, que combina a formação geral, humanística, crítica e reflexiva com a formação profissionalizante e prática é expressamente previsto no art. 3. ${ }^{\circ}$, que assim dispõe:

O curso de graduação em Direito deverá assegurar, no perfil do graduando, sólida formação geral, humanística e axiológica, capacidade de análise, domínio de conceitos e da terminologia jurídica, adequada argumentação, interpretação e valorização dos fenômenos jurídicos e sociais, aliada a uma postura reflexiva e de visão crítica que fomente a capacidade e a aptidão para a aprendizagem autônoma e dinâmica, indispensável ao exercício da Ciência do Direito, da prestação da justiça e do desenvolvimento da cidadania.

Os críticos dessa concepção de ensino jurídico argumentam que os cursos de direito devem estar voltados tão somente à formação profissional (especificamente à formação de advogados), bem como devem prioritariamente 
capacitar os estudantes para serem aprovados nos exames para ingresso na OAB. Alegam ainda que a carga horária dedicada às disciplinas propedêuticas que possibilitam a formação geral, humanística, reflexiva e crítica constituem um entrave para uma maior verticalização do ensino das disciplinas profissionalizantes, obstando um melhor desempenho dos bacharéis no exercício da advocacia e no exame da OAB. Propõem que o ensino do curso de direito enfatize uma especialização nas disciplinas profissionalizantes, em detrimento das disciplinas propedêuticas, de forma a eliminá-las da estrutura curricular ou reduzir significativamente as suas cargas horárias caso a primeira hipótese não seja possível.

Entendemos que tal proposta pretende ressuscitar o obsoleto modelo de ensino tecnicista que priorizava a formação profissionalizante, cujos efeitos nocivos já tivemos oportunidade de analisar.

Em que pese tal modelo estar superado, é importante trazermos algumas contribuições para o debate, uma vez que os defensores do seu resgate colocam em perigo as conquistas históricas do novo modelo representa.

Vamos analisar primeiramente a ênfase à especialização, ou seja, o argumento que o curso de direito deve prioritariamente formar advogados. Obviamente, um curso de direito tem por missão capacitar seus alunos para o exercício profissional. Todavia, o curso de direito não pode restringir sua formação à advocacia, uma vez que há, por óbvio, outras profissões jurídicas cuja vocação os alunos almejam exercer, as quais o curso de direito também deve possibilitar a formação.
Cláudio de Moura e Castro ${ }^{13}$ produziu um artigo bastante importante acerca da compreensão da especialização na atualidade, cujas lições são significativas para elucidar tal aspecto:

Bernard Shaw disse que um especialista é uma pessoa que sabe cada vez mais sobre cada vez menos. A frase é engraçadinha, porém errada. Cadê o especialista que só sabe de um assunto? Certamente, não está nos empregos mais cobiçados. [...]

[...] Portanto, o que conta não é o conhecimento especializado - inegavelmente necessário na pesquisa e em muitas outras áreas -, mas a combinação deste com uma série de competências generalizadas. Ou seja, todo especialista de primeira linha é também um excelente generalista. [...]

[...] É interessante notar que as grandes multinacionais contratam "especialistas" para posições subalternas e, para boa parte das posições mais elevadas, pessoas com a melhor educação disponível, qualquer que seja o diploma.

A profissionalização mais duradoura e valiosa tende a vir mais do lado genérico do que do especializado. Entender bem o que leu, escrever claro e comunicar-se, inclusive em outras línguas, são os conhecimentos profissionais mais valiosos. Trabalhar em grupo e usar números para resolver problemas, pela mesma forma, é profissionalização. E quem suou a camisa escrevendo ensaios sobre existencialismo, decifrando Camões ou Shakespeare pode estar mais bem preparado para uma empresa moderna do que quem aprendeu meia dúzia de técnicas, mas não sabe escrever.

A lição é muito clara: o profissional de primeira linha pode ou não ser um especialista, dependendo da área. Pode ou não ter a necessidade de conhecer as últimas teorias da moda. Mas não pode prescindir dessa "profissionalização genérica", sem a qual será

${ }^{13}$ Economista, Professor, Mestre pela Universidade de Yale, PhD em Economia pela Universidade de Vanderbilt, Ex-Diretor Geral da CAPES. 
um idiota, cuspindo regras, princípios e números que não refletem um julgamento maduro do problema. Portanto, lembremo-nos: especialista não é quem sabe de um só assunto, e ser profissional não é apenas conhecer técnicas específicas. O profissionalismo mais universal é saber pensar, interpretar a regra e conviver com a exceção. ${ }^{14}$

Os problemas decorrentes da especialização também são objeto dos estudos de Edgar Morin, sobretudo no contexto do mundo globalizado, demostrando os equívocos de se conceber o estudo do direito desatrelado dos conteúdos desenvolvidos nas disciplinas propedêuticas:

De fato, a hiperespecialização impede tanto a percepção do global (que ela fragmenta em parcelas), quanto do essencial (que ela dissolve). Impede até mesmo de tratar corretamente os problemas particulares, que só podem ser propostos e pensados em seu contexto. Entretanto, os problemas essenciais nunca são parcelados e os problemas globais são cada vez mais essenciais. Enquanto a cultura geral comportava a incitação à busca da contextualização de qualquer informação ou idéia, a cultura científica e técnica disciplinar parcela, desune e compartimenta os saberes, tornando cada vez mais difícil a sua contextualização. [...]

O conhecimento especializado é uma forma particular de abstração. A especialização "abstrai", em outras palavras, extrai um objeto de seu contexto e de seu conjunto, rejeita os laços e as intercomunicações com seu meio, introduz o objeto no setor conceptual abstrato que é o da disciplina compartimentada, cujas fronteiras fragmentam arbitrariamente a sistemicidade (relação da parte com o todo) e a multidimensionalidade dos fenômenos; conduz à abstração matemática que opera de si própria uma cisão com o concreto, privilegiando tudo o que é calculável e passível de ser formalizado.

${ }^{14}$ CASTro, C. M. Crônicas de uma educação vacilante. Rio de Janeiro: Rocco, 2005. p. 169-171.
Assim, a economia, por exemplo, que é a ciência social matematicamente mais avançada, é também a ciência social e humanamente mais atrasada já que se abstraiu das condições sociais, históricas, políticas, ecológicas inseparáveis das atividades econômicas. É por isso que seus peritos são cada vez mais incapazes de interpretar as causas e as conseqüências das perturbações monetárias e das bolsas, de prever e de predizer o curso econômico, mesmo em curto prazo. Por conseguinte, o erro econômico torna-se a consequiência primeira da ciência econômica. ${ }^{15}$

Pozenato também refuta a proposta do ensino profissionalizante no âmbito universitário, conforme se depreende dos seus ensinamentos:

Um erro comum a muitos que freqüentam cursos universitários é o de pretender que a Universidade deva se preocupar exclusivamente com a habilitação profissional. Assim o candidato ao magistério quer aprender aquilo que vai utilizar na profissão futura, o candidato à administração quer conhecer as técnicas de administração que lhe são úteis, e assim por diante. Ocorre, porém, que em qualquer profissão há o perigo da cristalização. Um engenheiro altamente capacitado para o momento presente, se não souber progredir será amanhã um profissional defasado. Mais do que o treinamento profissional, é sobretudo a atitude investigadora o elemento mais importante do ensino superior. $\mathrm{Na}$ Universidade o aluno deverá aprender a investigar, saber qual é o significado e quais são as exigências da investigação para que possa, com esse impulso inicial, permanecer numa atitude de progresso científico. ${ }^{16}$

A partir de tais reflexões, fica evidente que o argumento da especialização dos bacharéis em direito, em decorrência do

\footnotetext{
${ }^{15}$ MORIN, E. Os sete saberes necessários à educação do futuro. São Paulo: Cortez, 2000. p. 41-42.

16 PAVIANI, J. e POZENATO, J. C. Op. cit., p. 43.
} 
ensino profissionalizante, encontra-se superado, por tratar-se de um modelo ultrapassado e que não atende aos objetivos acadêmicos, muito menos às expectativas do perfil desejado dos egressos dos alunos do ensino superior previstas pelas diretrizes curriculares estabelecidas pelo Ministério da Educação.

Outro argumento que não merece prosperar é que o curso de direito deve estar voltado prioritariamente para capacitar os alunos para serem aprovados no exame de ingresso nos quadros da OAB. Primeiramente, é importante resgatar as reflexões anteriormente apresentadas, de que o curso de direito não pode estar voltado única e exclusivamente para a formação de advogados. Portanto, direcionar a formação dos alunos para serem bem sucedidos no Exame da Ordem dos Advogados é cometer o mesmo equívoco que o ensino médio acabou incorrendo ao preparar prioritariamente os alunos para o vestibular, ou seja, conferir ao curso de direito um caráter meramente instrumental ao invés de um caráter formativo (por meio da conjugação do conhecimento profissional e geral). O resultado da experiência do ensino médio foi um ensino meramente voltado à armazenagem de informação, descurando-se do ensino formativo, que possibilita a capacidade de leitura, de interpretação e de reflexão, fazendo com que os alunos dele egressos tenham uma grande dificuldade de adaptarse às exigências do ensino superior quando tais habilidades lhes são exigidas.

É importante ressaltar que tal crítica direciona-se ao argumento de que o curso de direito dever priorizar que os alunos estejam capacitados para serem aprovados no Exame da OAB. Obviamente, este é um dos objetivos do curso de direito, porque as novas diretrizes curriculares de 2004 estabelecem que o curso de direito deve possibilitar a formação profissional e, dentre tais habilidades, destaca a "adequada atuação técnico-jurídica, em diferentes instâncias, administrativas ou judiciais, com a devida utilização de processos, atos e procedimentos". (art. $4^{\circ}$., inciso IV). Porém, o desenvolvimento de tal habilidade não ocorre apenas no contexto da advocacia, uma vez que há muitas carreiras jurídicas para as quais o curso de direito deve preparar seus alunos. Pensar-se um curso de direito voltado precipuamente para a aprovação para o exame da $\mathrm{OAB}$, seria deixar no limbo um número significativo de alunos que pretendem seguir outras carreiras, tais como a de juiz, a de promotor e a de professor dentre outras.

Os defensores do ressuscitamento do modelo profissionalizante-tecnicista asseveram que as disciplinas propedêuticas, enquadradas no eixo de formação fundamental na Resolução n. ${ }^{\circ}$ 09/2004, constituem um empecilho para um maior aprofundamento do ensino voltado à habilitação profissional, aduzindo que os conteúdos nelas desenvolvidos não contribuem para a atuação do advogado, bem como para o Exame da OAB e que, portanto, deveriam ser expungidas do currículo do curso de direito ou então serem reduzidas as suas cargas horárias.

Tal aspecto envolve várias reflexões. Primeiramente, os conteúdos das disciplinas propedêuticas não podem deixar de serem contemplados na estrutura curricular, eis que tal atitude estaria desrespeitando as diretrizes curriculares e tal aspecto seria avaliado negativamente pelas Comissões de Avaliação do INEP (Instituto Nacional de 
Estudos e Pesquisas Institucionais Anísio Teixeira), que é o órgão encarregado pelo Ministério da Educação para aferir as condições de oferta dos cursos de graduação. Porém, nesta hipótese, não se pode deixar de registrar que o maior prejuízo seria causado aos bacharéis de direito, decorrente da lacuna existente na sua formação humanística, reflexiva e crítica.

Outro aspecto a ser ponderado, trata-se de um equívoco presente nas premissas do argumento de que as disciplinas propedêuticas constituem óbice para aprofundar a formação profissional. Nada impede que o curso de direito desenvolva, concomitantemente, uma consistente formação humanística, reflexiva e crítica e uma sólida formação profissionalizante. Elas não são incompatíveis ou excludentes, pelo contrário, são complementares e trazem grandes contribuições para a missão formativa (não se restringindo a um ensino meramente informativo) que deve nortear os cursos superiores.

Argumenta-se ainda que os conteúdos das disciplinas propedêuticas não são exigidos no Exame da $\mathrm{OAB}$, propondo a redução das suas cargas horárias para enfatizar o ensino voltado para a preparação para o exame. Assevera-se ainda que os baixos índices de aprovação no Exame exigem um reforço na carga horária das disciplinas profissionalizantes em detrimento das propedêuticas. Porém, não há qualquer evidência de que as disciplinas propedêuticas são responsáveis pelo insucesso dos bacharéis em direito no Exame da OAB. Pelo contrário, a reflexão sobre o desempenho no Exame da OAB deveria ser colocada a partir dos seguintes questionamentos: Será que existe um nexo de causalidade entre os conteúdos desenvolvidos nas disciplinas propedêuticas e o baixo desempenho dos bacharéis no Exame da OAB? Será que se houvesse uma redução da carga horária das disciplinas propedêuticas não haveria um desempenho inferior do que os alunos vem atualmente apresentando? Será que os maus resultados apresentados no Exame da OAB não decorrem da peculiaridade de que as disciplinas profissionalizantes não estarem sendo ministradas com a eficiência com que deveriam? Será que os conteúdos programáticos das disciplinas profissionalizantes estão sendo desenvolvidos na sua integralidade? Será que a vertificalização do estudo das disciplinas profissionalizantes não poderia ser realizada utilizando-se os horários vagos existentes nas grades horárias ao invés de reduzir-se a carga horária das disciplinas propedêuticas?

Os defensores da implementação do ensino baseado no modelo meramente profissionalizante-tecnicista no curso de direito alegam que os conteúdos desenvolvidos nas disciplinas propedêuticas (por exemplo, Filosofia ou Sociologia) não são utilizados pelos advogados para elaborarem seus arrazoados jurídicos e que o curso de direito não se presta a formar filósofos ou sociólogos, e que tal particularidade as torna prescindíveis na estrutura curricular. Para responder a esta alegação, as lições de Marilena Chaui são por si só eloqüentes, dispensando maiores comentários:

[...] Essa pergunta, "Para que Filosofia", tem sua razão de ser.

Em nossa cultura e em nossa sociedade, costumamos considerar que alguma coisa só tem o direito de existir se tiver alguma finalidade prática, muito visível e de utilidade imediata. Por isso, ninguém pergunta para que as 
ciências, pois todo mundo imagina ver a utilidade das ciências nos produtos da técnica, isto é, na aplicação científica da realidade. [...] Parece, porém, que o senso comum não enxerga algo que os cientistas sabem muito bem. As ciências pretendem ser conhecimentos verdadeiros, obtidos graças a procedimentos rigorosos de pensamento; pretendem agir sobre a realidade, através de instrumentos e objetos técnicos; pretendem fazer progressos nos conhecimentos, corrigindo-os e aumentando-os. Ora, todas essas pretensões das ciências pressupõem que elas acreditam na existência da verdade, de procedimentos corretos para bem usar o pensamento, na tecnologia como aplicação prática de teorias, na racionalidade dos conhecimentos, porque podem ser corrigidos e aperfeiçoados.

Verdade, pensamento, procedimentos especiais para conhecer fatos, relação entre teoria e prática, correção e acúmulo de saberes: tudo isso não é ciência, são questões filosóficas. $\mathrm{O}$ cientista parte delas como questões já respondidas, mas é a Filosofia quem as formula e busca respostas para elas.

Assim, o trabalho das ciências pressupõe, como condição, o trabalho da Filosofia, mesmo que o cientista não seja filósofo. No entanto, como apenas os cientistas e filósofos sabem disso, o senso comum continua afirmando que a Filosofia não serve para nada. [...]

O primeiro ensinamento filosófico é perguntar: O que é útil? Para que e para quem algo é útil? O que é o inútil? Por que e para quem algo é inútil?

O senso comum de nossa sociedade considera útil o que dá prestígio, poder, fama, riqueza. Julga o útil pelos resultados visíveis das coisas e das ações, identificando utilidade e a famosa expressão "levar vantagem em tudo". Desse ponto de vista, a Filosofia é inteiramente inútil e defende o direito de ser inútil.

Não poderíamos, porém, definir o útil de outra maneira? [...]

Qual seria, então, a utilidade da Filosofia?

Se abandonar a ingenuidade e os preconceitos do senso comum for útil; se não se deixar guiar pela submissão às idéias dominantes a aos poderes estabelecidos for útil; se buscar compreender a significação do mundo, da cultura, da história for útil; se conhecer o sentido das criações humanas nas artes, nas ciências e na política for útil; se dar a cada um de nós e à nossa sociedade os meios para serem conscientes de si e de suas ações numa prática que deseja a liberdade e a felicidade para todos for útil, então podemos dizer que a Filosofia é o mais útil de todos os saberes de que os seres humanos são capazes. ${ }^{17}$

Para refutar ainda este ponto de vista, são precípuos os ensinamentos de Pierre Bourdieu, constantes na aula inaugural proferida no Collège de France em 23.04.85:

[...] Se os que têm algo a ver com a ordem estabelecida, seja lá o que for, não gostam nem um pouco da sociologia, é porque ela introduz uma liberdade em relação à adesão primária que faz com que a própria conformidade assuma um ar de heresia ou de ironia. ${ }^{18}$

A ilação lógica a que se chega é que o antagonismo instaurado entre as disciplinas propedêuticas e profissionalizantes é uma falácia, pois como vimos anteriormente, todas elas são importantes e todas contribuem para a formação dos bacharéis de direito. Além disso, a formação humanista, reflexiva e crítica não é apenas uma meta das disciplinas propedêuticas, uma vez que todas as disciplinas da estrutura curricular são responsáveis por tal formação, assim como constitui missão das disciplinas propedêuticas contextualizarem seus conteúdos com situações concretas da realidade social e jurídica.

Como se pode perceber, os defensores do modelo profissionalizante- tecnicista adotam

17 CHAUI, M. Convite à Filosofia. São Paulo: Ática, 1994. p. 13;18.

${ }^{18}$ BOURDIEU, P. Lições de Aula. 2.ed. São Paulo: Ática, 2003. p. 60. 
uma atitude maniqueísta, olvidando os malefícios que a referida proposta causou no passado para a formação dos bacharéis de direito. Neste particular, é relevante resgatar os ensinamentos de Edgar Morin, acerca das conseqüências perniciosas do conhecimento fragmentado:

Efetivamente, a inteligência que só sabe separar fragmenta o complexo do mundo em pedaços separados, fraciona os problemas unidimensionalmente o multidimensional. Atrofia as possibilidades de compreensão e de reflexão, eliminando assim as oportunidades de um julgamento corretivo ou de uma visão a longo prazo. Sua insuficiência para tratar nossos problemas mais graves constitui um dos mais graves problemas que enfrentamos. De modo que, quanto mais os problemas se tornam multidimensionais, maior a incapacidade de pensar sua multidimensionalidade; quanto mais a crise progride, mais progride a incapacidade de pensar a crise; quanto mais planetários tornam-se os problemas, mais impensáveis eles se tornam. Uma inteligência incapaz de perceber o contex to e o complexo planetário fica cega, inconsciente e irresponsável.

Assim, os desenvolvimentos disciplinares das ciências não só trouxeram as vantagens da divisão do trabalho, mas também os inconvenientes da superespecialização, do confinamento e do despedaçamento do saber. Não só produzimos o conhecimento e a elucidação, mas também a ignorância e a cegueira. ${ }^{19}$

Como advertimos no início deste trabalho, as conquistas civilizacionais encontram-se num equilíbrio precário, pois os perigos que colocariam em risco sua existência podem a qualquer momento manifestarem-se. Para tanto, precisamos ficar alertas para defendê-las sempre que for

19 MORIN, E. A cabeça bem-feita: repensar a reforma, reformar o pensamento. Rio de Janeiro: Bertrand Brasil, 2004. p. 14-15. necessário. Nesta medida, somos todos responsáveis pela proteção do processo civilizatório, contra as manifestações autoritárias, despóticas e opressivas que o ameaçem.

Tais preocupações devem também estar presentes dentro dos cursos de direito, uma vez que a proposta de resgatar o modelo do profissional tecnicista para orientar o ensino nesses ministrado, constitui uma situação de perigo, fazendo-se necessária a defesa do novo modelo de ensino jurídico concebido com o advento da LDB e das diretrizes curriculares.

A análise dos modelos de ensino jurídico ministrados nos cursos de direito não foi arbitrária, muito menos infrutífera. Ele nos permitiu verificar que no passado, a concepção meramente profissionalizante do ensino dos cursos de direito teve conseqüências funestas. Neste particular, Walter Benjamin leciona na sua Teoria da História, que o resgate do passado acontece quando o presente vive uma situação de perigo, que o passado neste momento preciso se revela ao presente.

Ao apresentar a experiência nefasta do ensino profissionalizante-tecnicista sobretudo nos cursos jurídicos, o presente trabalho visa alertar as suas conseqüências extremamente perniciosas para a formação dos bacharéis de direito. Trata-se, como já mencionado, de utilizar o passado como um instrumento de reflexão do presente.

Para concluir, transcrevo a seguir a Tese VI de Walter Benjamin, como um contributo ${ }^{20}$

20 Nosso propósito é produzir uma reflexão sobre o tema, fundada em argumentos científicos, consoante os ensinamentos de Pierre Bourdieu constantes na aula inaugural proferida no Collège de France que anteriormente fizemos referência, 
à reflexão da responsabilidade ${ }^{21}$ do corpo docente e discente dos cursos de direito acerca da função e da importância das disciplinas propedêuticas na estrutura curricular nos cursos de direito:

publicada no Brasil sob o título Lições de Aula. 2.ed. São Paulo: Ática, 2003. p. 13, 14; 25: “[...] Sem dúvida, o sociólogo não é mais o árbitro imparcial ou o espectador divino, o único a dizer onde está a verdade - ou, para falar em termos do senso comum, que tem razão -, e isso leva a identificar a objetividade a uma distribuição eqüitativa dos erros e das razões. Mas o sociólogo é aquele que se esforça por dizer a verdade das lutas que têm como objeto entre outras coisas - a verdade. Por exemplo: em lugar de estabelecer uma divisão entre aqueles que afirmam e aqueles que negam a existência de uma classe, de uma região ou de uma nação, trabalha no sentido de estabelecer a lógica específica dessa luta, e de determinar, através de uma análise do estado da relação de forças e dos mecanismos de sua transformação, as chances dos diferentes campos. Cabe-lhe construir um modelo verdadeiro das lutas pela imposição da representação verdadeira da realidade, que contribuem para fazer a realidade tal como se apresenta ao registro" [...] "Se há uma verdade, é que a verdade é um resultado de lutas; mas essa luta só pode conduzir à verdade quando obedece a uma lógica tal que não se pode triunfar sobre os adversários sem empregar contra eles as armas da ciência, contribuindo assim para o progresso da verdade científica”.

${ }^{21}$ Utilizamos o termo "responsabilidade" no sentido concebido por Max Weber no seu estudo sobre a ética das decisões apresentado na conferência “A Política como Vocação” proferida em 1919. Weber identifica dois tipos de ética: a da convicção e a da responsabilidade, as quais tratam-se de etapas de um processo decisório. A ética da convicção é também conhecida como a ética do "tudo ou nada", na qual busca-se atingir um objetivo, sem que o agente considere as conseqüências dos seus atos. A ética da responsabilidade é aquela na qual o agente leva em consideração as conseqüências da decisão, onde a ciência traz a sua contribuição, sendo que a decisão cabe ao agente defini-la. Sobre esta temática, sugerimos a leitura da referida conferência na obra Ensaios de Sociologia. 5.ed. Rio de Janeiro: Guanabara Koogan, 1982. p. 97-153.
Articular historicamente o passado não significa conhecê-lo "como ele de fato foi". Significa apropriar-se de uma reminiscência, tal como ela relampeja no momento de um perigo. Cabe ao materialismo histórico fixar uma imagem do passado, como ela se apresenta no momento de perigo, ao sujeito histórico, sem que ele tenha consciência disso. $\mathrm{O}$ perigo ameaça tanto a existência da tradição como os que a recebem. Para ambos, o perigo é um mesmo: entregar-se às classes dominantes, como seu instrumento. Em cada época, é preciso arrancar a tradição ao conformismo, que quer apoderar-se dela. Pois o Messias não vem apenas como o Salvador; ele vem também como o vencedor do Anticristo. O dom de despertar no passado as centelhas da esperança é privilégio exclusivo do historiador convencido de que também os mortos não estarão em segurança se o inimigo vencer. E esse inimigo não tem cessado de vencer. ${ }^{22}$

\section{REFERÊNCIAS:}

BENJAMIN, W. Obras escolhidas: magia e técnica, arte e política. 3.ed. São Paulo:

Brasiliense, 1987.

BOURDIEU, P. Lições de Aula. 2.ed. São Paulo: Ática, 2003.

\section{CASTRO, C. M. Crônicas de uma educação} vacilante. Rio de Janeiro: Rocco, 2005.

CHAUI, M. Convite à Filosofia. São Paulo: Ática, 1994.

FARIA, J. E. e CAMPILONGO, C. F. A Sociologia Jurídica no Brasil. Porto Alegre: Sérgio Antônio Fabris ed., 1991

JUNQUEIRA, E. B. A Sociologia Jurídica no Brasil: introdução ao debate atual. Rio de Janeiro: Lumen Juris, 1993.

22 BENJAMIN, W. Obras escolhidas: magia e técnica, arte e política. 3.ed. São Paulo: Brasiliense, 1987. p. 224-225. 
LÔBO, P. L. Neto. O novo conteúdo mínimo dos cursos jurídico. In: OAB ENSINO JURÍDICO: Novas Diretrizes Curriculares, Conselho Federal da OAB, Brasília, 1996, p. 10-11.

MARX, K. O 18 Brumário e Cartas a

Kugelmann. 7.ed. Rio de Janeiro: Paz e Terra, 2002.
MORIN, E. Os sete saberes necessários à educação do futuro. São Paulo: Cortez, 2000.

PAVIANI, J. e POZENATO, J. C. A

Universidade em debate. Caxias do Sul:

EDUCS, 1980.

WEBER, M. Ensaios de Sociologia. 5.ed. Rio de Janeiro: Guanabara Koogan, 1982. 